\title{
The Freshmen's Metacognitive Awareness of Reading Strategies
}

\author{
Retno Wulan Dari \\ Universitas Negeri Surabaya \\ Surabaya, Indonesia \\ retnowulan@unesa.ac.id
}

\author{
Jannatul Laily Noviabahari \\ Universitas Islam Negeri Sunan Ampel \\ Surabaya, Indonesia \\ noviabahari@gmail.com
}

\begin{abstract}
This study focused on the metacognitive awareness of reading strategy employed by the freshmen and its relation to academic performance. A questionnaire called MARSI (Metacognitive Awareness of Reading Strategies Inventory Version 1.091 by Mokhtari and Reichard was used to gather the data from 91 freshmen of an English Department. In this study, not only the data from the questionnaire, but the participants' GPA were also used in this study. The results indicated that only 2.2\% participants are not aware of their use of reading strategy, while the rest of them are quite adapt to the strategies. The data also suggested that the participants prefer the Problem-solving strategies (PROB) most than the Global reading strategies (GLOB) and Support strategies (SUP). Moreover, there was an indication $(0.247$ at sig $0.018<0.05)$ that the use of metacognitive reading strategies correlated to the freshmen's academic performance. Based on the results of the study, better reading courses must be designed so that they can fulfill the students' need in terms of metacognitive reading strategy exposure.
\end{abstract}

Keywords-metacognitive; reading strategy; freshmen; GPA; academic performance

\section{INTRODUCTION}

For university students, reading skill is an indispensable skill. Studies have shown that the student's academic succes is heavily dependent on how well they read [1]-[5]. That being said, poor readers usually struggle in not only catching up with the literature. They need to read but also keeping up their academic perfomance. However, most of the students enrolled without realizing that good reading skill will play an utmost role in defining their academic succes.

During their study, university students are assigned to read a significant amount of reading materials, and most of them are not easy. Most of reading materials in university are textbooks, journal articles, essays, and other materials that required students to think critically. These kinds of material are quite complex and demanding. Having no proper reading comprehension ability, the students will fail to grasp the concepts and ideas presented in the text.

Moreover, the fact that the reading material in university is getting more and more difficult in each semester adds more problem to this condition. Very often, the students do not know what to do with their reading assigments. They know that they have to read it, but they do not know how to read it. They are overwhelmed by the complex vocabularies, the structure of the passage and cannot meet the academic expectation. A study reported that the students with poor reading skills took longer time to understand and comprehend the course materials than those with better reading skills on workload, and this lead to failure to complete the courses [2]. When repeated, this failure will lead to a condition in which the students resist to participate in reading [6]. Hence, those who read well, hold all the academic aces.

Nonetheless, reading is a complex process. It involves both cognitive and metacognitive procedure [4], [7]. Reading is a cognitive procedure because it involves characters decoding to form meaning [8]. It involves the reader, the text and the author [8], [9]. Thus, successfull reader can be defined as a reader who can get optimal information fom the text.

However, to be proficient readers, the students not only have to understand and interpret what they read, but they also have to make use their metacognitive strategy to check their comprehension and ponder on the material they read. Metacognitive reading strategies as described as "intentional, carefully planned techniques by which learners monitor or manage their reading" [10]. Furthermore, a number of study highlighted the importance of the use metacognitive strategy in reading [7], [11]-[14]. Based on those studies, it can be conclude that metacognitive reading strategies, when applied properly, can enhance the readers' understanding of the reading materials.

Many studies, report that feshmen tends to struggle during their first year in university in terms of keeping up with their reading loads and the difficulity of their tertiary-level reading materials [1], [6], [15]-[17]. This condition occurs because of the students do not pose a good reading habbit and strategies during their secondary level education.

In the other hand, on tertiary level education, the students are expected to be independent reader who can read difficult reading materials. Most colleges and universities design reading courses to cater their expectation. These reading courses are usually a part of the curriculum and are compulsory courses. Thus, upon the completion of these courses, it is expected that the student's reading skill will be much better compare to that when they were freshmen. However, even though they have passed the reading courses, many senior students still experience difficulities in using the right reading 
strategies when they have to read long and complex reading materials such as textbooks and scientific articles.

Studies have been conducted to investigate the ESL/EFL stident's reading skills and strategies at tertiary institutions. Most of these studies tend to facus on how the applications af eading strategies affect the students reading comprehension. There are also a growing number of studies comparing the metacognitive reading strategies used by EFL/ESL students while reading the English and Non-English reading material. However, a few studies on students reading abilities and stategies at university level have been conducted, especially in Indonesia.

A study investigates the student's use of metacognitive reading strategies focusing on analytic and pragmatic reading strategies when reading in the two languages English and Bahasa Indonesia has been conducted in 2007 [18]. The findings of this study indicated that the student's use different reading stategies when reading in LI and L2. It stated that students tend to use the analytic reading strategies reading in L1, and in contrary, when they reading in L2, they will use the pragmatic reading strategies. Another study reported the lest proficient learners's metacognitive reading strategi in Indonesia [19]. Even though the sample used in this study is quite small (40 students), this study finds out that the students tend to use Problem solving strategy than Global and Support strategies when they read $\mathrm{L} 2$ reading passages.

As indicated above, there have been little studies concerning the metacognitive awareness and the use of reading strategies by the tertiary level students in Indonesia, especially the freshmen. Focusing on the metacognitive reading strategies of the freshmen, this study tries to answer these following questions;

1. How often do the freshmen use the metacognitive reading strategy?

2. What are the most and least frequent reading strategies employed by the freshmen?

3. Are there significant relationship between the students' metacognitive reading strategy and the students' academic performance?

\section{METHOD}

\section{A. Subjects}

The participants in this study consisted of 91 freshmen majoring English Education Department. The participants were $25(27.5 \%)$ male students and $66(72.5 \%)$ female students who have undergone their first semester.

\section{B. Instruments}

The Metacognitive Awareness of Reading Strategies Inventory (MARSI) Questionnaire was administered to gather the data needed. The MARSI Questionnaire was developed by Mokhtari [10] as a tool to measure the awareness and reading strategies of the students when reading academic materials. The 30 questions of this questionnaire cover three subscales of reading strategies, those are; Global Reading Strategies or
GLOB (13 questions), Problem-Solving Strategies or PROB (8 questions), and Support Reading Strategies or SUP (9 questions).

In this study, the MARSI questionnaire were tested to make sure whether the questionnaire reliable for the subjects or not. The internal consistency reliability coefficients for the subscales were as follows: GLOB (0.89), PROB (0.90), and SUB (0.89). Moreover, for the overall scale's reliability was 0.80 , which suggest reliable measure of metacognitive awareness of reading strategies.

In addition, the students' were asked to report their GPA they acquired from the first semester. The data from students' GPA will be used in measuring the relationship between the students' metacognitive reading strategy and the students' academic performance.

\section{Data collection and analysis}

The MARSI Questionnaire was administered during a reading course in the second semester with the help of two reading course instructors. First, the instructors explained the purpose and the nature of the survey, and then the students were asked to do the questionnaire by giving their honest answer towards the questions. After the students finished doing the MARSI questionnaire, the students are asked to do the background questionnaire. This questionnaire was employed to get information about the participants' gender, age, and GPA score.

After the data gathered, the data were coded and analyzed using descriptive statistical procedures and Pearson coefficient correlation. The descriptive statistical procedures were used to find out about the freshmen' metacognitive reading strategy, while Pearson coefficient correlation was conducted to examine whether significant relationship between the students' metacognitive reading strategy and the students' academic performance exist or not.

\section{RESULTS AND DISCUSSION}

To answer the first research questions-How often do the freshmen use the metacognitive reading strategy?, descriptive statistics were used to find the frequency of overall metacognitive reading strategy employed by the students. Moreover, the students' score were grouped into three categorized; High (mean $\geq 3.5$ ), Medium (mean=2.5-3.4), and Low (mean $\leq 2.4)$. As shown in Table I., $47(51.6 \%)$ freshmen reported high use of metacognitive reading strategy, $42(46.2 \%)$ freshmen reported medium use, and only $2(2.2 \%)$ reported low strategy use.

TABLE I. The Freshmen's RePORTED Used of METACOGNITIVE READING STRATEGY

\begin{tabular}{|l|c|c|c|c|}
\hline & N & \% & M & SD \\
\hline HIGH & 47 & 51.6 & & \\
\cline { 1 - 3 } MED & 42 & 46.2 & \multirow{2}{*}{3.52} & 0.46 \\
\cline { 1 - 3 } LOW & 2 & 2.2 & & \\
\hline Total & 91 & 100.0 & & \\
\hline
\end{tabular}


From the explanation above, it can be seen that most of the freshmen are familiar with metacognitive reading strategy. Even though they are still in their first year in university, they seem quite adapt to of effectively planning, monitoring and evaluating their reading. This finding also corresponds with other previous study on metacognitive reading strategy employed by the freshmen [20]-[22].

With regard to the second research questions posed in this study- What are the most and least frequent reading strategies employed by the freshmen?, Table II. presents the descriptive statistics for mean frequency of the three subscales of metacognitive reading strategy employed by the freshmen. The table indicates that the Problem-solving strategies (PROB) are the most used strategies by the freshmen $(\mathrm{M}=3.84, \mathrm{SD}=0.57)$, followed by Global reading strategies (GLOB) $(\mathrm{M}=3.38$, $\mathrm{SD}=0.44$ ), and the last one is Support strategies (SUP) $(\mathrm{M}=3.35, \mathrm{SD}=0.57)$.

Several studies [21]-[23] on the students' metacognitive reading strategy also reported similar finding that the Problemsolving strategies are the most frequent used while the Support strategies are the least chosen. The fact that the students preferred the Problem Solving strategies than the other two indicates that the students face difficulties in reading academic materials quite often. Additionally, since the Support strategies are the least preferred one, it is likely that the students need more exposure to critical reading exercises, such as underlining important point, note taking and summarizing.

TABLE II. THE FRESHMEN'S PERCEIVED USED OF THE THREE SUBSCALES OF METACOGNITIVE READING STRATEGY $(\mathrm{N}=91)$

\begin{tabular}{|c|c|c|c|}
\hline Item & M & SE & SD \\
\hline PROP & 3.84 & 0.06 & 0.57 \\
\hline GLOB & 3.38 & 0.05 & 0.44 \\
\hline SUP & 3.35 & 0.06 & 0.60 \\
\hline
\end{tabular}

In addition, Table III. below shows the most and least frequent reading strategies perceived by the freshmen. The most frequent strategy used by the students is Re-reading difficult text to get better understanding (PROB27) with $\mathrm{M}=4.25$ \& $\mathrm{SD}=0.94$, followed by Trying to get back on track when lose concentration (PROB11), Paying closer attention (PROB16), Reading slowly (PROB8), and Guessing the meaning of unknown words or phrases (PROB30). Re-reading difficult text to get better understanding and Trying to get back on track when lose concentration are considered ineffective and inefficient strategy since it prolonged the reading process [19]. This strategy is usually used by struggling readers since they cannot effectively used another strategy to compensate their difficulties [13]. It means that even though the students are capable to use metacognitive reading strategy, they still need to familiarize themselves to compensation reading strategies.
TABLE III. THE FRESHMEN'S PERCEIVED USED OF THE READING STRATEGY $(\mathrm{N}=91)$

\begin{tabular}{|c|c|c|c|}
\hline Item & Mean & Std. Error & Std. Deviation \\
\hline PROB27 & 4.25 & 0.10 & 0.94 \\
\hline PROB11 & 4.09 & 0.09 & 0.86 \\
\hline PROB16 & 4.05 & 0.10 & 0.99 \\
\hline PROB8 & 3.98 & 0.10 & 0.95 \\
\hline PROB30 & 3.93 & 0.10 & 0.92 \\
\hline SUP15 & 3.93 & 0.11 & 1.05 \\
\hline SUP12 & 3.88 & 0.12 & 1.19 \\
\hline GLOB3 & 3.84 & 0.09 & 0.89 \\
\hline GLOB26 & 3.69 & 0.09 & 0.90 \\
\hline GLOB29 & 3.64 & 0.10 & 0.99 \\
\hline PROB21 & 3.61 & 0.11 & 1.00 \\
\hline GLOB1 & 3.47 & 0.09 & 0.82 \\
\hline GLOB25 & 3.45 & 0.09 & 0.87 \\
\hline PROB13 & 3.42 & 0.10 & 0.98 \\
\hline SUP28 & 3.34 & 0.11 & 1.01 \\
\hline GLOB4 & 3.33 & 0.12 & 1.16 \\
\hline SUP20 & 3.31 & 0.10 & 0.94 \\
\hline SUP9 & 3.31 & 0.10 & 0.95 \\
\hline SUB24 & 3.30 & 0.09 & 0.88 \\
\hline GLOB19 & 3.27 & 0.11 & 1.02 \\
\hline GLOB22 & 3.26 & 0.11 & 1.08 \\
\hline PROB18 & 3.23 & 0.10 & 0.99 \\
\hline GLOB14 & 3.22 & 0.10 & 1.00 \\
\hline SUP5 & 3.20 & 0.14 & 1.33 \\
\hline GLOB7 & 3.18 & 0.09 & 0.89 \\
\hline GLOB17 & 3.10 & 0.12 & 1.17 \\
\hline SUP2 & 3.08 & 0.13 & 1.21 \\
\hline GLOB23 & 3.02 & 0.08 & 0.77 \\
\hline SUP6 & 2.78 & 0.10 & 0.98 \\
\hline GLOB10 & 2.75 & 0.12 & 1.10 \\
\hline
\end{tabular}

On the other hand, the least frequent strategy used by the students is Skimming to note text characteristics (GLOB10) with $\mathrm{M}=2.75 \& \mathrm{SD}=1.10$, followed by Summarizing (SUP6), Analyzing and evaluating the information (GLOB23), Taking notes (SUP2), and Using tables, figures, and pictures (GLOB17). This finding indicates that the freshmen do not overview the text before they read it. They tend to ignore the text characteristics, tables, figures and pictures. Moreover, the data also suggest that the freshmen do not critically analyze and evaluate the reading material. One possible explanation for the 
lack of willingness to critically analyze and evaluate the reading material might be the engagement of personal interest [24]. Students will be motivated to read more if the materials suits their personal interest. Therefore, instructors should consider the students' interest when choosing reading materials. The students also need to be introduced to more reading activity that can motivate them to do close reading and reading beyond task completion.

In answering the last research question, Are there significant relationship between the students' metacognitive reading strategy and the students' academic performance?, Pearson coefficient correlation was used to find out whether the students' metacognitive reading strategy correlates to the students' academic performance or not. The results, as shown in Table IV., indicated that there is positive relationship between the students' metacognitive reading strategy and academic performance even though the magnitude of the relationship is not strong $(0.247$ at sig $0.018<0.05)$.

This finding is in line with that found in previous study on metacognitive awareness and academic achievement-that metacognitive skills have positive impact on students' academic achievement [25]-[28]. In this study, the weak correlation between the students' metacognitive reading strategy and academic performance might appear because of using single semester GPA instead of cumulative GPA.

TABLE IV. PEARSON COEFFICIENT CORRELATION BETWEEN THE Students' METACOGNITIVE READING STRATEGy AND ACADEMIC PERFORMANCE

\begin{tabular}{|c|l|c|c|}
\hline \multicolumn{2}{|c|}{} & $\begin{array}{c}\text { OVERALL } \\
\text { MARSI SCORE }\end{array}$ & GPA \\
\hline $\begin{array}{c}\text { OVERALL } \\
\text { MARSI } \\
\text { SCORE }\end{array}$ & Pearson Correlation & 1 & $.247^{*}$ \\
& Sig. (2-tailed) & & .018 \\
& $\mathrm{~N}$ & 91 & 91 \\
\hline \multirow{3}{*}{ GPA } & Pearson Correlation & $.247^{*}$ & 1 \\
& Sig. (2-tailed) & .018 & \\
& N & 91 & 91 \\
\hline \multicolumn{2}{|c|}{ *. Correlation is significant at the 0.05 level (2-tailed). } \\
\hline
\end{tabular}

\section{CONCLUSION}

One of the purposes of this study was to investigate the freshmen's metacognitive awareness of reading strategy and its relation to academic performance. The results showed that the majority of freshmen were high and medium users of metacognitive reading strategy. The most used strategies belong to the Problem-solving strategies (PROB while the least used strategies belong to Support strategies (SUP). This study also revealed that the top five reading strategies were categorized under Problem-solving strategies (PROB), while the least used reading strategies were belong to Global reading strategies (GLOB) and Support strategies (SUP). It means that even though the freshmen are familiar with metacognitive reading strategy, there was tendency for the freshmen to overlook simple yet important pre reading strategy such as skimming and overviewing the text before reading. Moreover, the results also indicated that the students were not familiar in applying strategies to sustain responsiveness to reading, especially summarizing and note taking. Further, this study also showed that the use of metacognitive reading strategy positively correlated to the freshmen's academic performance. However, similar to the other correlational studies, these findings did not imply causation. Since this study was limited only to the use of metacognitive reading strategies among the freshmen, further study covering more reading strategies and different level of education needs to be done to get more extensive data. Studies focused on which reading strategies that can be used as the academic performance predictor are also required.

\section{REFERENCES}

[1] S. R. Cox, D. L. Friesner, and M. Khayum, "Do Reading Skills Courses Help Underprepared Readers Achieve Academic Success in College?," J. Coll. Read. Learn., vol. 33, no. 2, pp. 170-196, 2003.

[2] S. Datta and M. Macdonald-Ross, "Reading Skills and Reading Habits: A Study of New Open University Undergraduate Reservees," Open Learn., vol. 17, no. December 2014, pp. 69-88, 2002.

[3] I. Hassan Taj, F. Ali, M. Aslam Sipra, and W. Ahmad, "Effect of Technology Enhanced Language Learning on Vocabulary Acquisition of EFL Learners," Int. J. Appl. Linguist. English Lit., vol. 6, no. 3, p. 262, 2017.

[4] J. Hermida, "The Importance of Teaching Academic Reading Skills in First-Year University Courses," Int. J. Res. Rev., vol. 3, no. September, pp. 20-30, 2009.

[5] B. Şentürk, "EFL Turkish University Students' Attitudes and Motivation Towards Reading in English," Procedia - Soc. Behav. Sci., vol. 199, pp. 704-712, 2015.

[6] M. E. Hoeft, "Why University Students Do not Read: What Professors Can Do To Increase Compliance," Int. Journals Scholarsh. Teach. Learn., vol. 6, no. 2, pp. 1-19, 2012.

[7] G. Bal, Õ. Õ, and T. Efe, "The Role of Metacognitive Activities on University Level Preparatory Class EFL Learners ' Reading Comprehension," vol. 232, no. April, pp. 294-299, 2016.

[8] M. Mohib Ullah and S. Fatema, "Why some students are less motivated in reading classes at Tertiary Level in Bangladesh," English Lang. Teach., vol. 6, no. 5, pp. 129-140, 2013.

[9] H. S. A. A. Samah and H. K. Jusoff, "Teaching Comprehension Skills using Context -Based Texts in Second Language Learning at Tertiary Level," Int. Educ. Stud., vol. 1, no. 4, pp. 118-123, 2008.

[10] R. Sheorey and K. Mokhtari, "Differences in the metacognitive awareness of reading strategies among native and non-native readers," vol. 29, pp. 431-449, 2001.

[11] F. Cubukcu, "Enhancing vocabulary development and reading comprehension through metacognitive strategies Metacognition," vol. 18, no. 1, pp. 1-11, 2008.

[12] M. Habibian, "The Impact of Training Metacognitive Strategies on Reading Comprehension among ESL Learner's.," J. Educ. Pract., vol. 6, no. 28, pp. 61-69, 2015.

[13] J. M. Magogwe, "Metacognitive awareness of reading strategies of University of Botswana English as Second Language students of different academic reading proficiencies," Read. Writ., vol. 4, no. 1, pp. 1-8, 2013.

[14] M. Reza Ahmadi, H. Nizam Ismail, and M. Kamarul Kabilan Abdullah, "The importance of metacognitive reading strategy awareness in reading comprehension," English Lang. Teach., vol. 6, no. 10 , pp. $235-244,2013$. 
[15] N. A. Boakye and N. A., "Extensive reading in a tertiary reading programme: Students' accounts of affective and cognitive benefits," Read. Writ., vol. 8, no. 1, p. 9 pages, 2017.

[16] G. M. Cupp, P. A. Dyer, T. F. Morrison, and S. M. Tracz, "The Relationship between Pleasure Reading, Textbook Reading \&amp; Academic Success," J. Coll. Read. Learn., vol. 23, no. 1, pp. 10-19, 1990

[17] K. Mokhtari and C. Reichard, "Investigating the strategic reading processes of first and second language readers in two different cultural contexts," vol. 32, pp. 379-394, 2004.

[18] M. Vianty, “The comparison of students' use of metacognitive reading strategies between reading in Bahasa Indonesia and in English," Int. Educ. J., vol. 8, no. 2, pp. 449-460, 2007.

[19] A. Pammu, Z. Amir, and T. N. R. T. M. Maasum, "Metacognitive Reading Strategies of Less Proficient Tertiary Learners: A Case Study of EFL Learners at a Public University in Makassar, Indonesia," Procedia - Soc. Behav. Sci., vol. 118, pp. 357-364, 2014.

[20] F. I. Jom'a, "Investigating Berziet Students' Awareness of their Knowledge and Use of Metacognitive Reading Strategies," Birzeit University - Palestine, 2013

[21] M. J. M. Estacio, "Bilingual Readers' Metacognitive Strategies as Predictors of Reading Comprehension Ma. Joahna Mante Estacio De La Salle University, Manila," vol. 10, no. February, pp. 179-199, 2013.

[22] T. K. Abu-Snoubar, "English as a Foreign Language Learners' Major and Meta-cognitive Reading Strategy Use at Al-Balqa Applied
University," English Lang. Teach., vol. 10, no. 9, p. 69, 2017.

[23] D. Fitrisia, K.-E. Tan, and Y. Q. Yusuf, "Investigating metacognitive awareness of reading strategies to strengthen students' performance in reading comprehension," Asia Pacific J. Educ. Educ., vol. 30, no. 2004, pp. 15-30, 2015.

[24] A. M. Sani, T. F. T. Ariffin, and S. Shaik-Abdullah, "I'll Read in English if...: A Glimpse into the Nature of Tertiary ESL Reading Motivation," Procedia - Soc. Behav. Sci., vol. 118, pp. 343-350, 2014.

[25] R. Abdellah, "Metacognitive Awareness and its Relation to Academic Achievement and Teaching Performance of Pre-service Female Teachers in Ajman University in UAE," Procedia - Soc. Behav. Sci., vol. 174, pp. 560-567, 2015.

[26] T. M. Chevalier, R. Parrila, K. C. Ritchie, and S. H. Deacon, "The Role of Metacognitive Reading Strategies, Metacognitive Study and Learning Strategies, and Behavioral Study and Learning Strategies in Predicting Academic Success in Students With and Without a History of Reading Difficulties," J. Learn. Disabil., vol. 50, no. 1, pp. 34-48, 2017.

[27] P. Panchu, B. Bahuleyan, and S. K, "the Role of Metacognitive Awareness of Reading Strategies As a Predictor of Academic Achievement.," Int. J. Adv. Res., vol. 4, no. 11, pp. 720-725, 2016.

[28] S. Kummin and S. Rahman, "The relationship between the use of metacognitive strategies and achievement in English," Procedia Soc. Behav. Sci., vol. 7, no. 2, pp. 145-150, 2010. 